Volume 2, Issue 1, 2016, p. 29-30

\title{
An interesting case of aluminum phosphide poisoning
}

\author{
Gholamreza Faridaalaee', Seyed Hesam Rahmani' ${ }^{2}$, Sajjad Ahmadi', Amin Mahboubi ${ }^{2 *}$
}

'Emergency Medicine Department, Maragheh University of Medical Sciences, Maragheh, Iran

2Emergency Medicine Department, Urmia University of Medical Sciences, Urmia, Iran

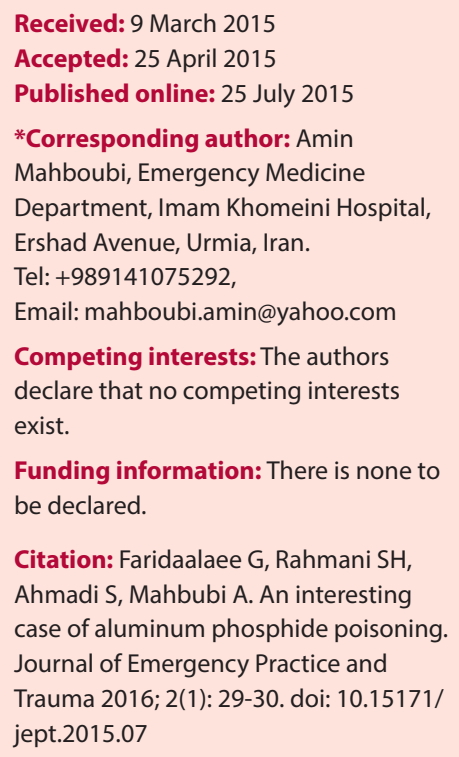

\begin{abstract}
Ingestion and inhalation of phosphine are 2 forms of toxicity and their clinical manifestation is extremely wide. A 22-year-old girl was admitted with complaints of nausea, vomiting and epigastric pain after eating lunch. She had a history of celiac disease. On arrival, she was alert and hemodynamically stable. There was not any abdominal tenderness or guarding. Food poisoning treatment initiated but after 1 hour her condition deteriorated with hypotension, tachycardia, and epigastric pain. Venous blood gas (VBG) showed severe metabolic acidosis. She denied any drug ingestion again. New Electrocardiogram (ECG) showed extensive inferolateral ST elevation myocardial infarction (STEMI). Bicarbonate plus dopamine was initiated. After 8 hours of admission, rhythm became ventricular fibrillation (VF) and cardiopulmonary resuscitation (CPR) began. Peritoneal dialysis was performed. Next morning frequent VF occurred again but CPR was unsuccessful. Family found aluminum phosphide (AIP) tablets in her purse. Early diagnosis and supportive treatment may be effective but the most important factor is the dose of ingestion.

Keywords: Aluminum phosphide, Poisoning, Survival, Prevention and control
\end{abstract}

\section{Introduction}

Aluminum phosphide (AlP), a rodenticide, pesticide and insecticide, is used to protect stored grains. It is also known as "rice tablet" (1). This material is available in solid tablet forms and is sold in closed metal containers. Once this tablet has a contact with moisture, it releases a highly toxic gas called phosphine (2). Therefore, ingestion of AlP tablet or inhalations of phosphine gas are considered as 2 ways for possible poisoning. The mortality rate of $30 \%$ to $50 \%$ has been reported in several articles and prognostic factors are still on research (2-4). This toxic material is easily available in some countries like Iran and India and that is why many articles on this topic are belonging to them. But this toxic material is restricted in some others countries like France and unintentional poisoning is usually included (2). Here we report another case of intentional poisoning with AlP to emphasize the importance and possible clinical manifestation.

\section{Case report}

A 22-year-old single girl was admitted to the emergency department of hospital with complaints of nausea, vomiting, and epigastric pain. Her symptoms abruptly started from 2 hours before admission and progressed afterwards. Based on her commenting, she was completely well prior to that. She also denied any trauma or drug ingestion. She had a positive history of celiac disease but did not use any medication regularly. On arrival, she was alert, without any apparent distress. Vital signs included pulse rate $=95$ beat per minute, blood pressure $=100 / 70 \mathrm{~mm} \mathrm{Hg}$, oral temperature $=36.8^{\circ} \mathrm{C}$ and respiratory rate $=18$ breath per minute and oxygen saturation $94 \%$ in room air. On physical examination, there was no positive finding except mild epigastric tenderness. Electrocardiogram (ECG) revealed mild sinus tachycardia. Some measures aimed at symptomatic treatment were performed. After 1 hour, epigastric pain became more severe and generalized blood pressure decreased to $90 / 60 \mathrm{~mm} \mathrm{Hg}$ and pulse rate increased to 105 beats per minute. Her level of consciousness also decreased. Laboratory tests, blood gas analysis, gastroenterology consult, and abdominal ultrasonography were requested. Venous blood gas (VBG) analysis showed severe metabolic and respiratory acidosis: $\mathrm{PH}=7.02, \mathrm{HCO}_{3}=10.9$ $\mathrm{mEq} / \mathrm{L}, \mathrm{PCO}_{2}=41.2 \mathrm{~mm} \mathrm{Hg}$. Other laboratory tests were reported in normal range. $\beta$-Human chorionic gonadotropin (BHCG) was negative either. Ultrasound showed mild plural effusion and abdominal free fluid that aspiration revealed as serosal. Despite fluid administration, the patient's condition deteriorated and blood pressure dropped to $80 / 50 \mathrm{~mm} \mathrm{Hg}$ and pulse rate increased to 130 beats per minute within 3 hours of admission. Secondary laboratory test results in 3 hours after admission were as 
follows: blood urea $=35 \mathrm{mEq} / \mathrm{L}$, creatinine $=2.56 \mathrm{mEq} / \mathrm{L}$, sodium $=142 \mathrm{mEq} / \mathrm{L}$, potassium $=7.3 \mathrm{mEq} / \mathrm{L}$. Secondary VBG analysis also showed worsened acidosis: $\mathrm{PH}=6.98$, $\mathrm{HCO}_{3}=9.3 \mathrm{mEq} / \mathrm{L}$ and $\mathrm{PCO}_{2}=38.7 \mathrm{~mm} \mathrm{Hg}$. Coagulation profile was disrupted $(\mathrm{PT}=25, \mathrm{PTT}=49$, INR $=3.29)$. Bicarbonate and dopamine was administered. An ECG was performed again, and it showed extensive inferolateral ST elevation myocardial infarction (STEMI). In echocardiography, ejection fraction was $15 \%$. After 8 hours of admission, ventricular fibrillation (VF) was appeared on monitoring. So cardiopulmonary resuscitation (CPR) began and rapid sequence intubation (RSI) was performed. After 3 hours resuscitation and reversing of spontaneous circulation (ROSC), the patient was transferred to the intensive care unit and peritoneal dialysis was performed to reverse the sever acidosis. Unfortunately, on the next day, frequent VF occurred again, but CPR was unsuccessful. After all, patient's family found "rice tablet" in her purse.

\section{Discussion}

AIP poisoning can affect multiple organs mainly gastrointestinal and cardiopulmonary systems (5). There is usually only a short interval between toxin ingestion and the symptoms appearance. The clinical manifestations include nausea, vomiting, hematemesis, epigastric pain; in combination with profound and refractory hypotension. Other cardiopulmonary signs include heart congestion, subendocardial infarction or pericarditis, focal necrosis, dysrhythmia, tachycardia, tachypnea, dyspnea, pulmonary edema, respiratory failure and cyanosis. Restlessness, dizziness, coma, and death are also predictable. ECG changes include ST segment elevation/depression, PR and QRS interval prolongation, heart block, VF and T-wave flattening $(3,6)$. The most common laboratory abnormalities include hypoxemia with severe metabolic acidosis. Liver dysfunction, coagulation profile disruption, hyperkalemia, and acute renal failure can also be reported $(1,2,7)$.

There is no antidote for AlP poisoning and supportive measures are usually all that can be offered. Early gastric lavage with potassium permanganate is commonly performed. But a combination of potassium permanganate, sodium bicarbonate and coconut oil has been also recommended in some literatures (8). Administration of charcoal and sorbitol suspension is also performed with hope to reduce absorption. Intravenous magnesium sulphate, sodium bicarbonate, calcium gluconate, and trimetazidine are administered to prevent or treat cardiac dysrhythmia and dysfunction. Moreover, fluid therapy, vasopressor, digoxin and intra-aortic balloon pump can be considered to beat the profound shock $(1,4)$.

Based on the studies which were carried out on case series, some prognostic factors have been introduced. Some authors mentioned that there was a significant difference between survival and nonsurvival according to mean arterial blood PH, bicarbonate concentration, and ECG abnormalities. In some other studies, those who died had taken higher amount of AlP tablet, presented with severe hypotension, and had poor liver function test com- pared with the patients who survived. It was claimed that time lag to medical attention can also influence the survival $(3,5,9,10)$.

As researches continue to achieve a standard effective treatment protocol in AlP poisoning, applying legal restrictions in order to curtail the access to this material may reduce the rate of exposure.

\section{Ethical issues}

Confidentiality of patient information was maintained.

\section{Authors' contributions}

All authors passed 4 criteria for authorship contribution based on recommendations of the International Committee of Medical Journal Editors (ICJME).

\section{References}

1. Mehrpour O, Jafarzadeh M, Abdollahi M. A systematic review of aluminium phosphide poisoning. Arh Hig Rada Toksikol 2012; 63(1): 61-73. doi: 10.2478/100041254-63-2012-2182,

2. Anger F, Paysant F, Brousse F, Le Normand I, Develay P, Galliard Y, et al. Fatal aluminum phosphide poisoning. J Anal Toxicol 2000; 24(2): 90-2.

3. Shadnia S, Sasanian G, Allami P, Hosseini A, Ranjbar A, Amini-Shirazi N, et al. A retrospective 7-years study of aluminum phosphide poisoning in Tehran: opportunities for prevention. Hum Exp Toxicol 2009; 28(4): 209-13. doi: 10.1177/0960327108097194.

4. Proudfoot AT. Aluminium and zinc phosphide poisoning. Clin Toxicol 2009; 47(2): 89-100. doi: 10.1080/15563650802520675.

5. Singh S, Singh D, Wig N, Jit I, Sharma BK. Aluminum phosphide ingestion-a clinico-pathologic study. J Toxicol Clin Toxicol 1996; 34(6): 703-6. doi: 10.3109/15563659609013832.

6. Moghadamnia AA. An update on toxicology of aluminum phosphide. Daru 2012; 20(1): 25. doi: 10.1186/2008-2231-20-25.

7. Bumbrah GS, Krishan K, Kanchan T, Sharma M, Sodhi GS. Phosphide poisoning: a review of literature. Forensic Sci Int 2012; 214(1-3): 1-6. doi: 10.1016/j. forsciint.2011.06.018.

8. Shadnia S, Rahimi M, Pajoumand A, Rasouli $\mathrm{MH}$, Abdollahi M. Successful treatment of acute aluminium phosphide poisoning: possible benefit of coconut oil. Hum Exp Toxicol 2005; 24(4): 215-8. doi: 10.1191/0960327105ht513oa.

9. Hosseinian A, Pakravan N, Rafiei A, Feyzbakhsh S. Aluminum phosphide poisoning known as rice tablet: a common toxicity in North Iran. Indian J Med Sci 2011; 65(4): 143-50. doi: 10.4103/0019-5359.104777.

10. Sharma A, Dishant VG, Kaushik JS, Mittal K. Aluminum phosphide (celphos) poisoning in children: a 5-year experience in a tertiary care hospital from northern India. Indian J Crit Care Med 2014; 18(1): 33-6. doi: 10.4103/0972-5229.125434. 